Nig. J. Pure \& Appl. Sci. Vol. 33 (Issue 1, 2020)
eISSN 2756-4045
Life Sciences, Univ. of Ilorin, Nigeria
www.njpas.com.ng

doi: http://dx.doi.org/10.48198/NJPAS/20.A05

\title{
SORPTION POTENTIALS OF MELON PEELS IN THE REMOVAL OF ULTRAMARINE RED (DYE) FROM AQUEOUS SOLUTION
}

Department of Chemistry, Delta State University, Abraka, Nigeria.

\begin{abstract}
This work was conducted in line with the efforts to remove coloured materials from waste water using non conventional techniques. Therefore, this study investigated the effectiveness and efficiency of melon (Cucumeropsis mannii) peels in the removal of ultramarine red, from aqueous solution. The dependence of sorption parameters (contact time, dosage, temperature and $\mathrm{pH}$ ) on dye removal were examined. Results obtained revealed that increase in the contact time between 20-100 minutes increased the dye adsorption. The maximum percentage of ultramarine red dye removed was obtained at 100 minutes. However, increase in dye concentration from $10-50 \mathrm{mg} / \mathrm{L}$, resulted to an increase in sorption capacity $(0437-1.062 \mathrm{mg} / \mathrm{g})$. The $\mathrm{pH}$ increase resulted to increase in ultramarine red adsorption. Meanwhile ultramarine red adsorption was also observed to increase from $0.054-0.079 \mathrm{mg} / \mathrm{g}$, while the temperature was varied between $30^{\circ}-70^{\circ} \mathrm{C}$. The data generated were further fitted to both Langmuir and Freunlich Isotherms. The separation factor $\left(\mathrm{S}_{\mathrm{F}}\right)$ from Langmuir was 0.48 . While the coefficient of determination from Freundlich $\left(\mathrm{R}^{2}\right)$ was 0.976 , indicating that both models were favourable to the adsorption process. Pseudo-second order kinetics produced a better description of the adsorption process than the pseudo-first order kinetics. The melon peel is a good adsorbent for the sorption of ultramarine red in aqueous solution.
\end{abstract}

Keywords: Ultramarine red, adsorption, melon peels, and sorption isotherm.

\section{Introduction}

Most coloured substances like dyes and pigments are of synthetic background and are made up of very complex aromatic molecular structure that make them very stable and difficult to biodegrade. Coloured materials are used in industries such as papers, plastic, food, textiles leather, cosmetics and so on. The wide use of these substances often poses pollution challenge because of coloured wastewater discharge into our water systems (Arami et al., 2005). This coloured wastewater does not only affect aesthetic value but reduces light penetration and consequently reduces several processes of photosynthesis (Arslanogwu et al., 2005).

It is therefore important to remove these coloured substances from the wastewater before they are discharged by industries (Azliar et al., 2005). Urgent attention is required so as to safeguard the environment and public health (Asiagwu et al., 2017 and Carliel, 1996). In line with the foregoing, a number of conventional techniques have been developed for the decontamination of these

\section{Corresponding Author: A.K. ASIAGWU}

Department of Chemistry, Delta State University, Abraka, Nigeria.

Email: drasiagwu@yahoo.com 
coloured substances from industrial effluents including adsorption, ion-exchange coagulation and membrane technology (Che, 2004). Adsorption appears more effective due to its sludge-free clean operations and almost

Page | 3609 completely removes coloured materials even from the diluted solutions (Chaing et al., 2004).

This present study was conducted to assess the sorption potentials of melon peels to remove ultramarine red from aqueous solution under varying kinetic variables.

\section{Materials and Methods}

\section{Preparation of ultramarine red dye solution}

The ultramarine red used in this work was from a commercial market without any further purification. The ultramarine red stock solution was made by dissolving $50 \mathrm{~g}$ accurately weighed dye in $1000 \mathrm{ml}$ of deionised water and made to required concentration for each of the experimental variables being investigated.

\section{Equipment/Apparatus}

The equipment/apparatus employed in this study include thermostatic bath, spectrometer, measuring cylinder, spatula, volumetric flask, whatman No. 45 filter paper, test tubes, digital balance, conical flask and $\mathrm{pH}$ meter.

\section{Sample Collection and Preparation of Adsorbent}

The adsorbent (melon peels) of about $3.5 \mathrm{~g}$ was obtained from a commercial market at Koko in Warri North Local Government Area of Delta State, and it was sun dried for several days. Then the dried melon peels were ground and sieved using $300 \mu \mathrm{m}$ sieve (Choy, 1999). The sieved adsorbent (melon peels) obtained was preserved in a container for further use in this study.

\section{Experimental Analysis}

\section{Effect of Stay Time on Adsorption}

The modified melon peels of $2 \mathrm{~g}$ were measured into five distinct conical flasks. The amount of $10 \mathrm{mg} / 1$ of the ultramarine red solution was prepared with deionized water. The $50 \mathrm{ml}$ of the ultramarine solution was measured into the five flasks. The conical flasks were further labeled for the different time intervals of 100, 80, 60, 40, 20 minutes. These flasks were tightly covered and further allowed to elute at their respective time intervals. The accompanying suspensions were further filtered with whatman No. 45 filter paper before it was centrifuged. The dye ion concentration was estimated by DR 2010 Spectrophotometer. (Gutnaz et al., 2004)

\section{Determination of the effect of adsorbent dosage on adsorption of the ultramarine red solution}

The 2, 3, 4, 5 and $6 \mathrm{~g}$ of the melon peels modified adsorbent were weighed into the five different flasks. $50 \mathrm{ml}$ of the ultramarine red solution were also weighed into the five distinct flasks. The conical flasks were further labeled for 2,3,4,5 and $6 \mathrm{~g}$ differences in dosage. The conical flasks were tightly covered then agitated for 20 minutes before the suspensions were filtered with whatman No. 45 filter paper and centrifuged. The accompanying ultramarine red ion concentration was estimated using DR 2010 spectrophotometer (Gutnaz et al., 2004).

Determination of the effect of dye ion concentration on the adsorption of ultramarine red

This work was carried out in-line with the previous works of Gutnaz et al. (2004). Different standard dye solution of $50,40,30,20 \& 10 \mathrm{mg} / \mathrm{g}$ were prepared. Only $50 \mathrm{ml}$ of each of the dye solution was added to weigh $2 \pm 0.01 \mathrm{~g}$ melon peels modified adsorbent in five separate flasks and then agitated for 20 minutes. Towards the end of the time, the resulting suspensions were filtered with Whatman 
No. 45 filter paper before it was centrifuged. The dye ion concentrations were obtained using DR 2010 spectrophotometer.

Determination of the effect of temperature on Page | 3610 the adsorption of ultramarine red in solution

This parameter investigates the effect of temperature on adsorption following the procedure as recommended by Gunmany, (2002). $2 \mathrm{~g}$ of melon peels (the adsorbent) was measured into five several conical flasks and the $50 \mathrm{ml}$ of the ultramarine red dye solution $(10 \mathrm{mg} / \mathrm{g})$ was weighed into the five different flasks. The flasks were further labeled for temperature readings of $30,40,50,60$ and $70{ }^{0} \mathrm{C}$. The conical flasks were then tightly covered and heated at their respective temperatures with thermostatic bath, at 20 minutes for each. To the end of each time, each of the flasks were brought out before being agitated for another 5 minutes. The resulting suspensions were filtered using whatman No. 45 filter paper before it was centrifuged. The dye ion concentrations were obtained using DR 2010 spectrophotometer.

\section{Determination of the effect of $\mathrm{pH}$ on adsorption of ultramarine red in solution}

Modified melon peels adsorbent $(2 \pm 0.01 \mathrm{~g})$ was weighed into (5) five different flasks. A $50 \mathrm{ml}$ of the ultramarine red dye solution $(10 \mathrm{mg} / \mathrm{l})$ was measured and poured into the different five flasks. The solutions were then, adjusted to $\mathrm{pH} 2.0,4.0$. 6.0, 8.0 and 10.0 by the introduction of a solution of $\mathrm{HCl}(0.1 \mathrm{~m})$ or $\mathrm{NaOH}(0.1 \mathrm{~m})$. The $\mathrm{pH}$ values were determined by the aid of $\mathrm{pH}$ meter. Thereafter the conical flasks were then covered and then agitated for 20 minutes. Towards the end, the suspensions were thus filtered with the use of the whatman No. 45 filter paper and centrifuged. The dye concentrations were determined with DR 2010 spectrophotometer. (Gunmany, 2002 and Gutnaz, 2004).

\section{Data Calculation}

Estimation of the degree of sorption of ultramarine red

The quantity of the ultramarine red adsorbed by the melon peels during the series of batch determinations were evaluated using the mass balance equation as expressed below: (Gunmany, 2002 and Hajira et al., 2008).

$$
q e=(C o-C e) \frac{V}{M}
$$

Where

$\mathrm{qe}=$ dye contents on the biomass $\left(\mathrm{mgg}^{-1}\right)$ at equilibrium.

$\mathrm{Ce}=$ dye concentration in solution $\left(\mathrm{mgL}^{-1}\right)$ at equilibrium.

$\mathrm{Co}=$ Initial dye concentration in solution $(\mathrm{mg} / \mathrm{l})$

$\mathrm{V}=$ Volume of dye solution used (ml)

$\mathrm{M}=$ mass of adsorbent used $(\mathrm{g})$

\section{Kinetic Interpretation of experimental results}

In the effort to fully understand the mechanism of adsorption process the pseudo-first-order and pseudo-second-order equations were utilized to treat the data. The linear flow of the pseudo-first order model is denoted by the equation. (Gunmany, 2002 and Hajira et al., 2008).

$\operatorname{In}(\mathrm{qe}-\mathrm{qt})=\operatorname{In} \mathrm{qe}-\mathrm{Kt}$

Where

$\mathrm{qe}=$ mass of dye adsorbed at equilibrium $\left(\mathrm{mgg}^{-1}\right)$

$\mathrm{qt}=$ mass of dye adsorbed at time $\mathrm{t}\left(\mathrm{mgg}^{-1}\right)$

$\mathrm{k}=$ equilibrium rate constant.

The linear plot of In (qe - qt) versus t confirms this model.

However, the linear representation of pseudosecond order equation is expressed as: 


$\begin{array}{lll}\underline{1}= & \underline{1}+ & \underline{\mathrm{t}} \\ \text { qt } & \text { ho } & \end{array}$

Page | 3611

Where

qt contents of the dye ion on the adsorbent surface $\left(\mathrm{mgg}^{-1}\right)$ at time $\mathrm{t}$. qe = quantity of dye adsorbed at equilibrium $\left(\mathrm{mgg}^{-1} \mathrm{~min}\right.$.) The initial adsorption rate, ho, is further defined by the equation $\mathrm{Ho}=\mathrm{K}_{2} \mathrm{qe}^{2}$

Where $\mathrm{K}_{2}$ represent the pseudo-second order rate constant (gmg ${ }^{-1}$ min.) (Gunmany, 2002 and Hajira et al., 2008).

\section{Results}

\section{Effect of Contact Time on Adsorption}

The response of time on adsorption was in order to obtain how long the melon peel waste biomass would take to absorb the ultramarine red. This was investigated between the intervals of 20 minutes and varied from 20 to 100 minutes. The data from the time-dependent experiment for the sorption of ultramarine red by the melon peel waste is shown in the fig. 1. It is evident that as contact time was increased from 20 to 100 minutes, the fractions of dye ions removed by the biomass increased. Consequently, the results obtained also revealed that the dye adsorbed by the melon peels is very rapid with increase in time, including the percentage of dye adsorbed in which maximum percent of 96 was obtained at 100 minutes. This may be attributed to the fact that, as the dye solution sorbent system was agitated at longer time, so much of the molecules of the ultramarine red accumulate on the surface of the adsorbate until equilibrium was attained.

Related observations have been made by some researchers (Gunmany, 2002; Gutnaz et al., 2004 and Hajira et al., 2008).

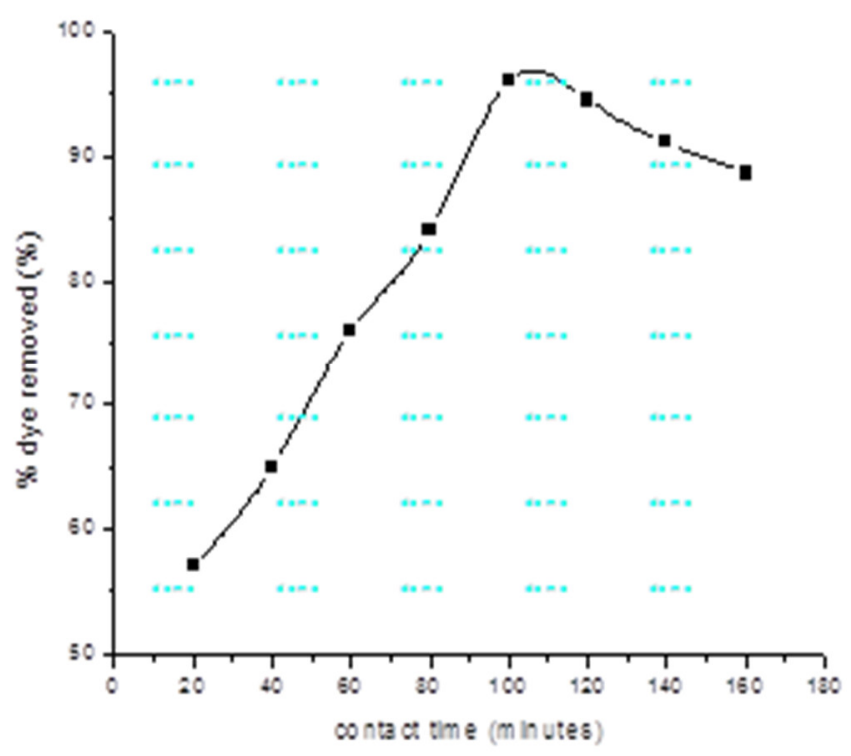

Fig.1: The effect of contact time on the adsorption of the dye

\section{Effect of dye ion concentration on adsorption}

The experimental result of the adsorption of ultramarine red onto the melon peel waste biomass at various initial dye ion concentrations is shown in fig. 2. The sorption capacity increased from 0.437 to $1.062 \mathrm{mg} / \mathrm{g}$ with increase in the amount of dye from 10 to $50 \mathrm{mgL}^{-1}$ having maximum adsorption of $1.062 \mathrm{mg} / \mathrm{g}$.

Similarly, the actual amount in percentage removed from solution was observed to increase with increase in initial dye concentration. This could be due to the fact that when the dye concentration is increasing, more dye is made available for adsorption on the adsorbent. It is also due to the effect of concentration gradient which is the principal driving force for the sorption process (Hiroyuki et al., 1994). 


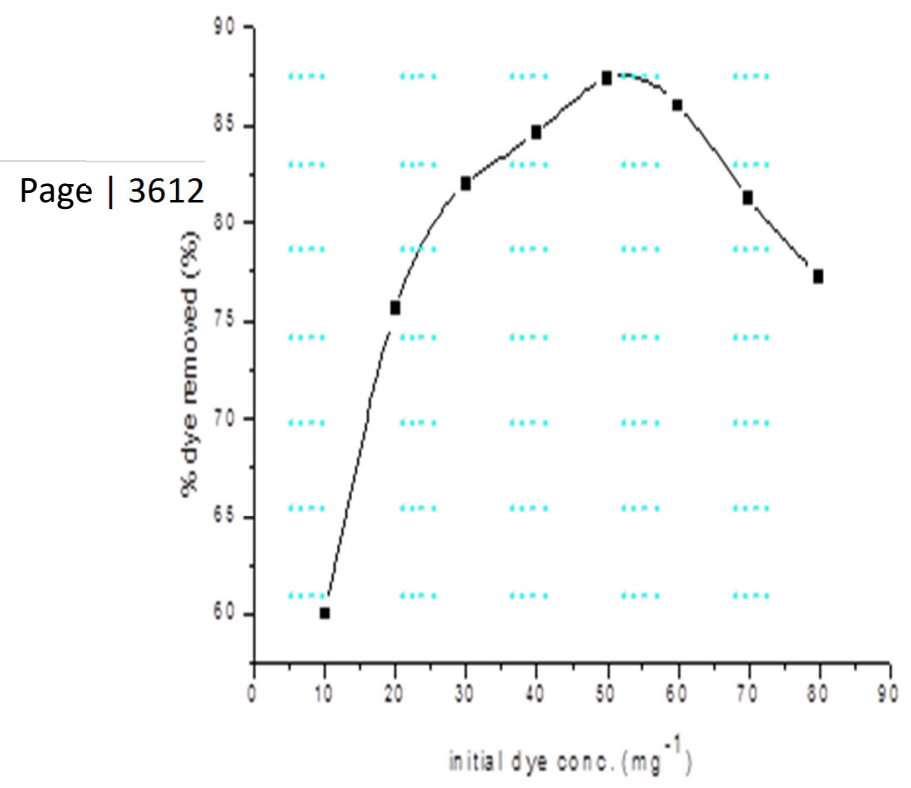

Fig. 2: Effect of concentration on dye removal

\section{Effect of pH on adsorption}

The $\mathrm{pH}$ of an aqueous system is a crucial factor that may affect the uptake of the adsorbate. The chemical characteristics of both adsorbent vary with $\mathrm{pH}$. According to Horsfall and Ho et al. (1996), most plant materials are made up of complex organic residues such as lignin and cellulose that contain several kinds of polar functional groups.

These groups can pertake in chemical bond formation and may therefore be responsible for the cation exchange characteristics of most biomaterials. The dependence of $\mathrm{pH}$ on adsorption of the dye is represented in fig 3 .

It was found out that when the $\mathrm{pH}$ of dye solution increased from 2 to 8 , the percentage of the ultramarine red adsorbed increased from 50-56. However, at $\mathrm{pH} 10$, there was a rapid decrease in the percentage of dye adsorbed. As reported by Horsfall et al. (2003), in the study of the removal of methylene blue by treated activated carbon, the

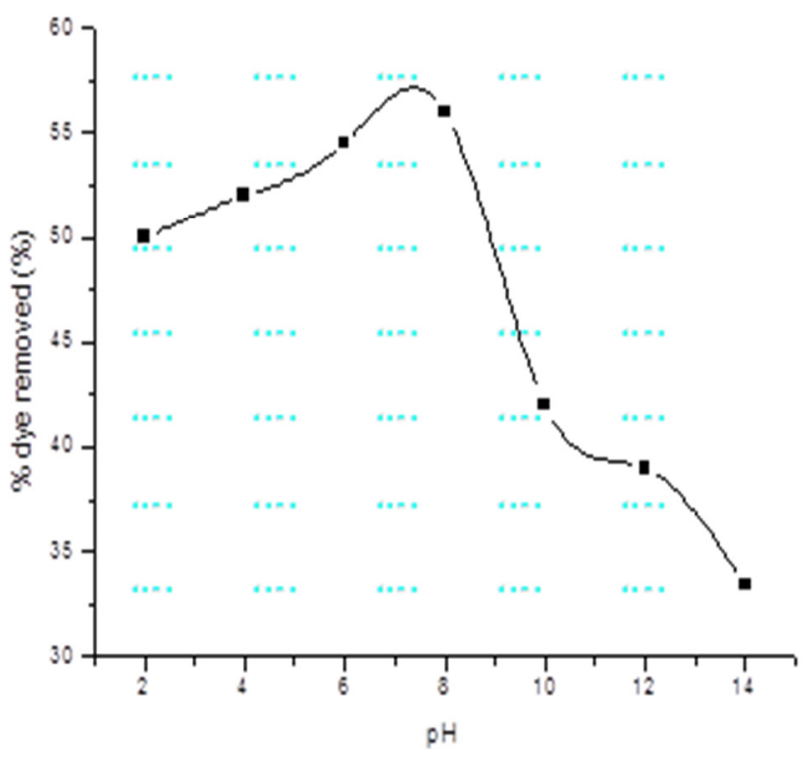

Fig.3: A plot of $\mathrm{pH}$ against dye adsorption efficiency at mass of biomass $2 \mathrm{~g}$, time 20 minutes, conc. $10 \mathrm{mg} / \mathrm{I}$ and volume $50 \mathrm{ml}$.

removal of methylene blue increased together with increase in $\mathrm{pH}$. However, the adsorption of the methylene blue at low $\mathrm{pH}$ may be due to the presence of hydrogen ions competing with the cation group on the ultramarine red adsorption sites. Meanwhile similar trend has been reported in literature for the adsorption of Congo red dye onto malua oil cake (Juang et al, 1996).

\section{Effect of adsorbent dosage on the adsorption process}

The effect of amount of biomass (melon peel) on the adsorption of the ultramarine red was investigated in which the quantity of biomass was varied from 2 to 9 (figure 4). From the results obtained the amount of the ultramarine red removed increased from 0.026 to $0.198 \mathrm{mg} / \mathrm{g}$ as the biomass was increased horn 2 to $6 \mathrm{~g}$. 


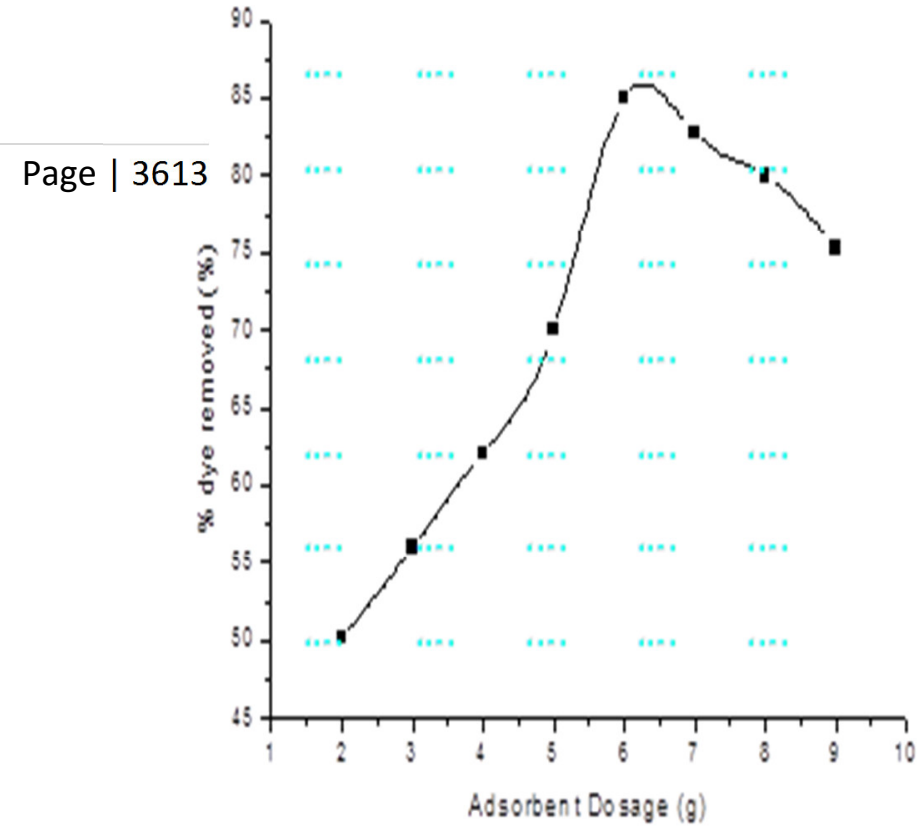

Fig. 4: Effect of adsorbent dosage on dye removal at Time 20 minutes, volume 50rn1, cone. $10 \mathrm{mg} / 1$.

From the fig. 4, it was observed that the optimum adsorbent dose was $6 \mathrm{~g}$ in which $0.198 \mathrm{mg} / \mathrm{g}$ of dye was adsorbed. Similarly, the maximum percentage 85 of dye adsorbed was obtained at the dosage $6 \mathrm{~g}$. Consequently, the increase the rate of dye uptake could be linked to certain reasons as reported Khan et al. (2002). The increase in ultramarine red uptake was due to the increasing biomass dosage as the binding sites for adsorption increased.

\section{Effect of Temperature on the adsorption of ultramarine red}

The dependence of ultramarine red sorption on temperature was investigated within the range of temperature $30^{\circ} \mathrm{C}$ to $70^{\circ} \mathrm{C}$ at the interval of $10^{\circ} \mathrm{C}$. The effect of temperature on the sorption of dye is shown figure 5. Results obtained from figure 5 showed that the contents of ultramarine red adsorbed increased from 0.054 to $0.079 \mathrm{mg} / \mathrm{g}$ with increase in temperature from 30 to $70^{\circ} \mathrm{C}$.

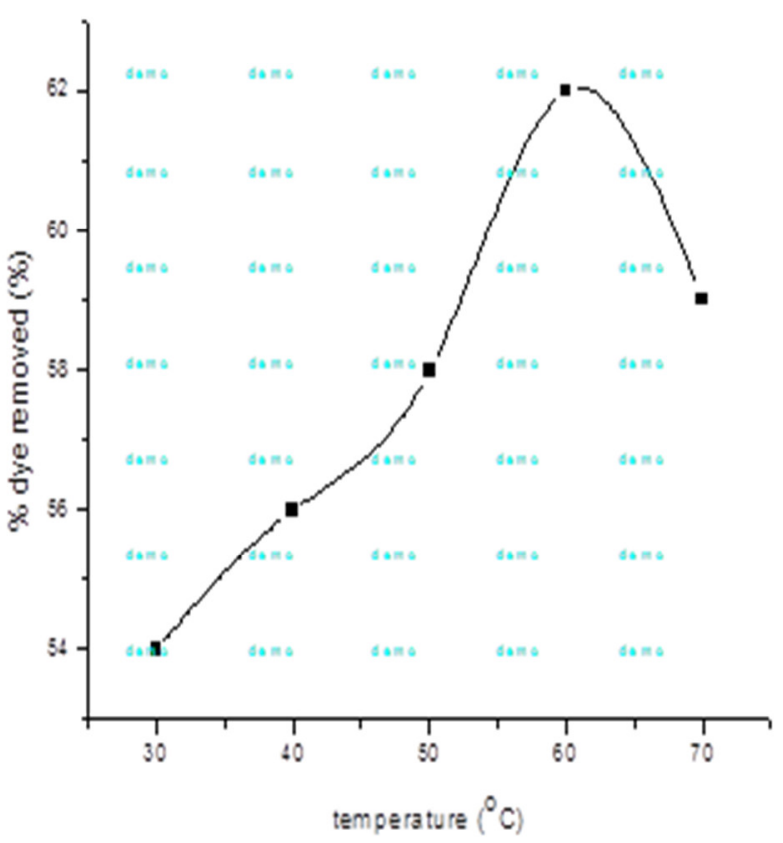

Fig.5: temperature dependence plot at mass of biomass $2 \mathrm{~g}$, volume $50 \mathrm{mI}$. Conc. $10 \mathrm{mg} / \mathrm{I}$.

However, this increase in the quantity of ultramarine red removed as the temperature increased was not much significant. Similar observation was made by Laowansiri (2008). The increase in adsorption due to the increased temperature could be linked to the chemical reaction occurring between the functional groups of the melon peels biomass and ultramarine red. Similarly, at higher temperature, there is the increase in mobility potentials of the larger dye ion producing a swelling effect on the internal structure of the biomass, if thus allows the larger dye molecules to penetrate further (Mishra et al., 2009). The reasons accompanying increase sorption process with increase temperature has been reported also by Carliel (1996). 


\section{Equilibrium studies}

\section{a. Langmuir Isotherm}

The model, Langmuir isotherm was used for the estimation of the maximum adsorption capacity Page | 3614 representing the complete monolayer overage on the biomass surface. The graphs of specific adsorption Ce/qe against the equilibrium concentration $\mathrm{Ce}$ is shown in fig (6) and the linear isotherm parameters. qm. $\mathrm{K}_{\mathrm{L}}$ and the co-efficient of determinations also contained in table 1 .

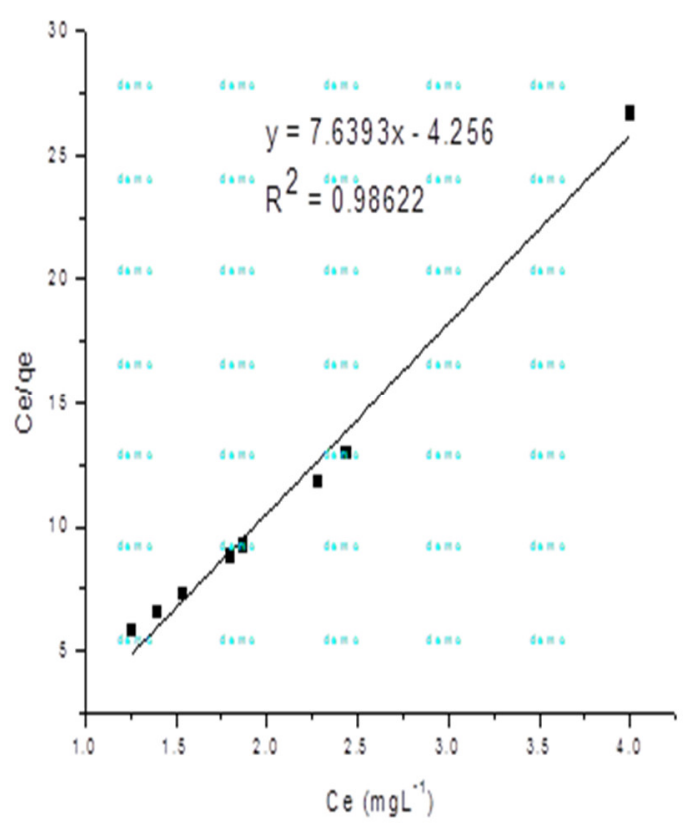

Fig. 6: Langmuir Equilibrium

The $\mathrm{R}^{2}$ result obtained suggests that the Langmuir isotherm is a good model of the adsorption. Langmuir isotherm defined in terms of a dimensionless constant referral to as separation factor $S_{F}$ (Choy, 1999 and Horsfall et al., 2003). This shown below:

$$
\mathrm{S}_{\mathrm{F}}=\frac{1}{1+\mathrm{K}_{\mathrm{L}} \mathrm{Co}}
$$

Where

The parameter indicates the shape of the isotherm as follows

$$
\begin{aligned}
& \mathrm{S}_{\mathrm{F}}>1 \quad \text { unfavorable isotherm } \\
& \mathrm{K}_{\mathrm{L}}=\quad \text { Langmuir isotherm constant } \\
& \mathrm{Co}=\quad \text { Initial ion quantity of 10mg/L. } \\
& \begin{array}{l}
0<\mathrm{S}_{\mathrm{F}}<1 \quad \text { favourable isotherm (Azliar et al., } \\
2005) .
\end{array} \\
& \mathrm{S}_{\mathrm{F}}=1 \quad \text { linear isotherm } \\
& \mathrm{S}_{\mathrm{F}}=0 \quad \text { irreversible isotherm } \\
& \text { The separation factor for the ultramarine red is less } \\
& \text { than one indicating that } \\
& \text { melon peel waste biomass is an excellent } \\
& \text { adsorption for the ultramarine red ions. The } \\
& \text { deparation parameter and other Langmuir isotherm } \\
& \text { parameters are shown below. }
\end{aligned}
$$

Table I: Linear Langmuir isotherm parameters

\begin{tabular}{lllll}
\hline Dye ion & $\mathbf{Q m}\left(\mathbf{m g}^{-1}\right)$ & $\mathbf{K L}\left(\mathbf{L g}^{-1}\right)$ & $\mathbf{R}^{\mathbf{2}}$ & $\mathbf{S}_{\mathbf{F}}$ \\
\hline Ultramarine Red & 0.6998 & 0.108 & 0.884 & 0.481 \\
\hline
\end{tabular}

\section{b. Freundlich Isotherm}

The Freundlich model was employed to evaluate the adsorption intensity of the ultramarine red by melon peels on the surface. The Linear Freundlich isotherm for the sorption of ultramarine ion into melon peel waste are represented in fig (7). Critical examination of the plot revealed that the Freundlich isotherm is also an appropriate model to describe the sorption process under consideration. Table (4) shows the linear Freundlich sorption isotherm constant and the co-efficient of determination $\mathrm{R}^{2}$.

Evident from the $\mathrm{R}^{2}$ value the linear representation of the Freundlich isotherm seem to produce a 
reasonable model for the sorption process under investigation.

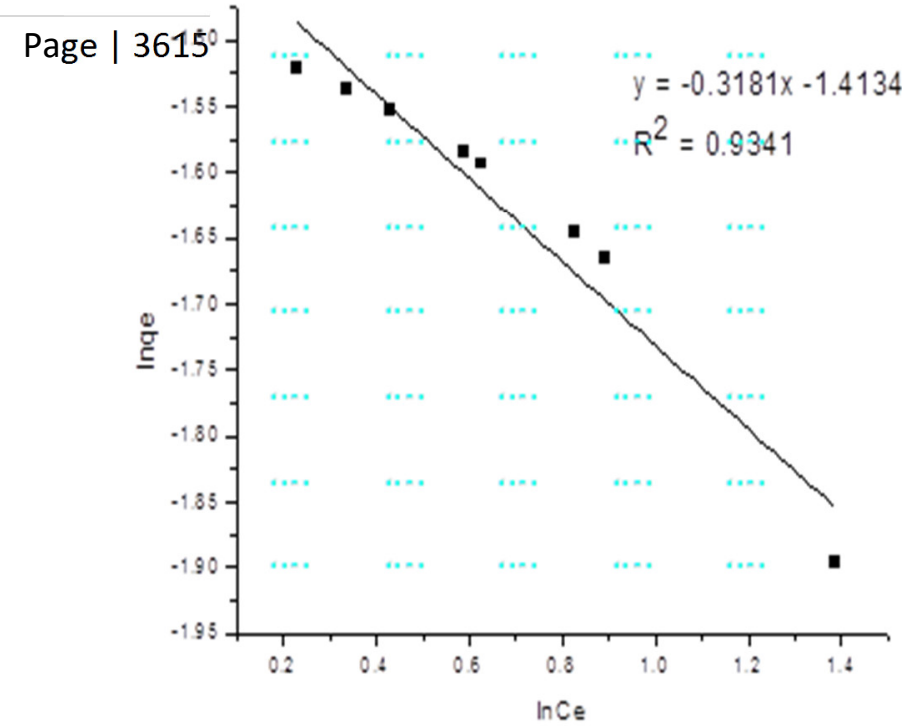

Fig. 7: Freundlich Equilibrium Isotherm Model

Table II: Freundlich Isotherm Constant

\begin{tabular}{llll}
\hline Dye ion & $\mathbf{1} / \mathbf{n}$ & $\mathbf{Q e}\left(\mathbf{m g g}^{-1}\right)$ & $\mathbf{R}^{\mathbf{2}}$ \\
\hline Ultramarine red & 1.747 & 0.038 & 0.9726 \\
\hline
\end{tabular}

\section{Kinetics of Sorption}

\section{a. Pseudo-first-order}

The kinetic of sorption is one of the essential factors in the rate at which sorption occurs for a system and very important in understanding sorption design and analysis with sorbate residence time and reactor dimension (Choy, 1999 and Horsfall et al., 2003).

The graph of In (qe-qt) against $t$ as shown below represents the pseudo-first order kinetics. From the flow, it is evident that the relationship between dye ion diffusivity, in (qe qt) and time is linear this confirms the model. In the figure 8 below, the value of the co-efficient of determination $\mathrm{R}^{2}$ is shown and the value represented that the pseudo-first order mode gave or produced a good description for the study.

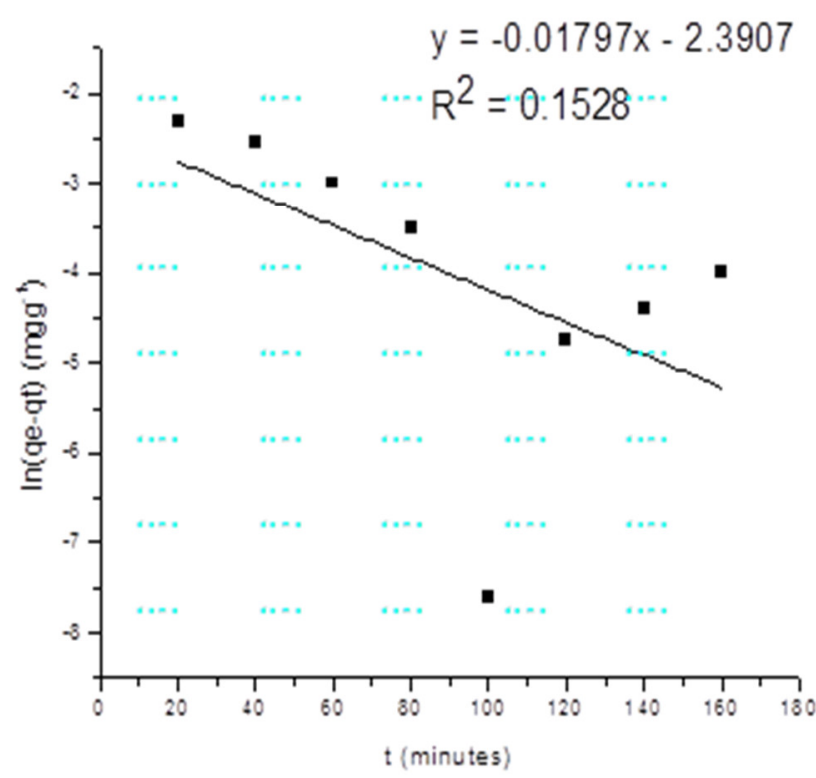

Fig. 8: Pseudo First Order Plot

Table III: Values for Pseudo - First order parameters

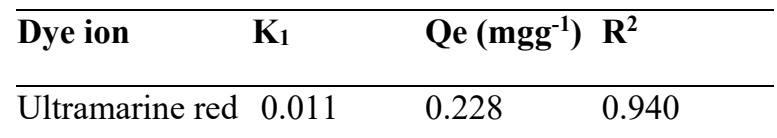

Consequently, the sorption kinetics showed high dependence on the physical and chemical quantities of the sorbent material, which also affects the sorption process and the mechanism (Arami and Azliar, 2005).

\section{b. Pseudo-Second Order Model}

The plot t/qt against $\mathrm{T}$ shown in the figure (9) represents the pseudo-second order kinetics arising from the flow, it is evident that the relationship between $t / q t$ and $t$ is linear which justifies the model. However, the initial sorption rate ho, the equilibrium adsorption capacity qe, the pseudo- 
second order rate parameter $\mathrm{K}_{2}$ and the co-efficient of prediction $\mathrm{R}^{2}$ are contained in table iv. Evident from the co-efficient of determination $\mathrm{R}^{1}$, the pseudo-second order model provide a better description for the process better than pseudoPage | 3616 second order model. Similar report has been made by Che (2004) for the adsorption of basic acid blue and direct red types via clay based and activated carbon.

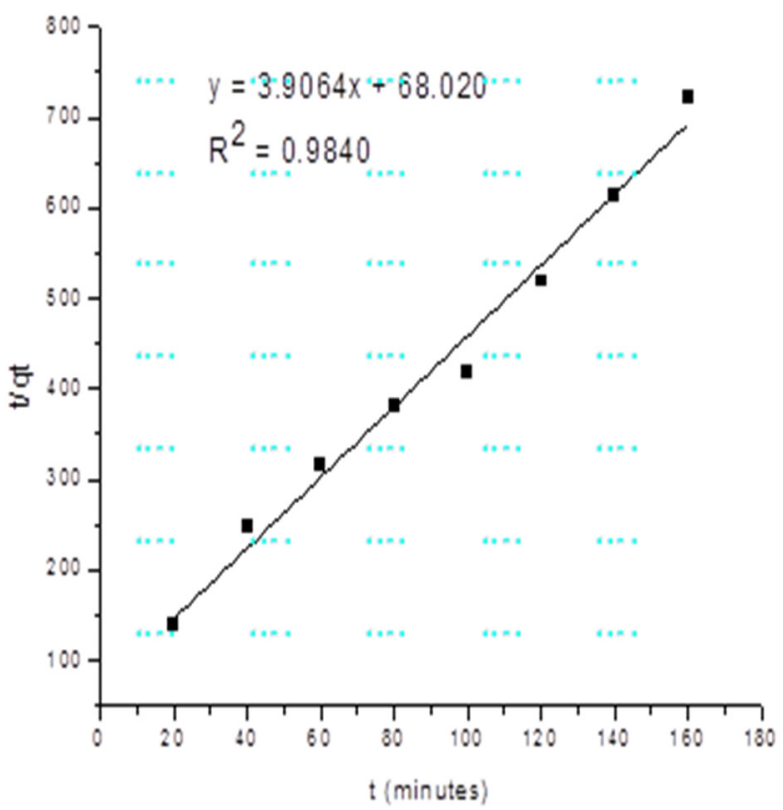

Fig. 9: Pseudo Second Order Plot

Table IV: Values of pseudo-second order parameter

\begin{tabular}{lcccc}
\hline Dye ion & $\begin{array}{c}\mathbf{H o} \\
\left(\mathbf{m g g}^{-1} \mathbf{m i n}^{-1}\right)\end{array}$ & $\begin{array}{c}\mathbf{K}_{2} \\
\left(\mathbf{m g g}^{-1} \mathbf{m i n}^{-1}\right)\end{array}$ & $\begin{array}{c}\mathbf{Q e} \\
\left(\mathbf{m g g}^{-1}\right)\end{array}$ & $\mathbf{R}^{\mathbf{2}}$ \\
\hline Ultramarine red & 0.009 & 0.026 & 0.592 & .9277
\end{tabular}

\section{Conclusion}

The effect of ultramarine red dye ion concentration on adsorption capacities showed that melon peel waste biomass adsorbed dye ions from solution, with an increase in sorption capacity of the biomass with increase dye ion concentration solution. The actual percentage sorption of the dye ions from solution also increased with increased in initial dye ion concentration.

The effect of contact time and temperature showed the same trend in the increase on the amount of dye adsorbed and the actual percentage removal. The $\mathrm{pH}$ studies showed that increase in $\mathrm{pH}$ increased the amount of dye adsorbed. However, the data fitted the Langmuir and Freundlich Models very well. The separation quantity or equilibrium parameter obtained from Langmuir isotherm showed that adsorption of dye ion onto the melon peel waste biomass is favorable. In general, the data showed that melon peel waste biomass was successful as biosorbent for the removal of dye ion from contaminated water and may serve as an alternate to conventional means. The kinetic data clearly established that pseudo second order model provide a more appropriate description of the dye ions adsorption process ultramarine red.

\section{References}

Arami, Limaee N.Y., Mahmood, N.M. and Tabrizi, N.S. (2005). "Removal of Dyes from Coloured Textile Wastewater by Orange Peels Adsorption: Equilibrium and kinetic Studies". Journal of Colloids Interface Science, 288: 371-376.

Arslanogwu, F.N., Kar, F. and Arisan, N. (2005). Adsorption of dark coloured compounds from Peach Pulp by using Powdered Activated carbon. Journal of Food Engineering, 71: 156-163.

Asiagwu A.K, Okposo M.A, Itoya P.O and Peretiemo - Clarke, B.O. (2017). Utilization of Modified Cashew Nut Shell As An Adsorbent for The Removal C57 Dyes From Aqueous Solution Via Kinetic Approach. Chemistry and Materials Research, 9(7), 110. 
Azliar, S.S., Liew, A.G., Suhardy, D., Hafiz, F.K. and Hatim, M.D.I. (2005). Dye Removal from Aqueous solution by using Adsorption on treated Sugarcane Bagasse. American Journal of Applied Science, 2(11), 1499-503.

Carliell, C. M. (1996). Treatment of exhausted reactive dye bath effluent using anaerobic digestion Laboratory and full scale trials. Water SA., 22: 225-233.

Che, A. Y. (2004). Adsorption studies of dyes using clay-based and Activated carbon adsorbent. Malaysian Journal of Analytical Science, 1 (17).

Chiang, H.L., Lin, K.F.L., Chen, S.Y., Choa, C.G. and Pan, S.D. (2004). Dye Adsorption on Biosolid Adsorbent. Province. Rhode Island, U.S.A., 11-16.

Choy, K. K. H. (1999). Sorption of acid dyes from effluents using Activated carbon. Resoir Conserv. Recycle, 27: 57-71.

Gunmany, A. (2002). Adsorption of Basic Dye on Strongly Chelating polymer: Batch kinetic studies. Iranian Polymer Journal, 11(4): 237-244.

Gutnaz.. O., Kaya, A., Matyar, F., and Arikan.. B. (2004). Sorption of Basic Dye on from aqueous solution by Activated Sludge. Journal of Hazardous Materials, 108: 183188.

Hajira, T., Muhammed S. and Qazi J. (2008). Removal of Basic dye Methylene blue by using Bioadsorbent Ulva. Journal of Biotechnology,7(15):2649-2655.

Hiroyuki, H., Fakudu, S., Okomoto, A. and Kataoka, T. (1994). Adsorption of acid dye cross-linked Chitosan Fibres.
Equilibrium/Chemical Engineering Science, 48 (12): 2261-2212.

Ho, Y.S., "Wast, D.A.J. and Foster C.F. (1996'). Kinetic studies of Competitive heavy metal Adsorption by Spfaggnum Moss peat Environmental Technology, 17: 71-77.

Horsfall, M. Jnr, Abia, A.A. ad Spiff, A.1. (2003). Removal of $\mathrm{Cu}$ (II) and $\mathrm{Zn}$ (II) ions from wastewater by cassava (Manihot Esculenta Cranze) waste viomass. African Journal of Biotechnology, 2(1 0):360-364.

Juang, R. S., Tseung, R. L., Wu, F. C. and Lin, S. 3. (1996). Use of Chitin and Chitosan in lobster shell waste for colour removal from aqueous solution. Journal of Environmental Science Health, A31: 325-338.

Khan, A. R., Uddin, F. and Ahmed, Z. (2002). Adsorption Behaviour of critic acid from aqueous solution on Activated Charcoal. Pakistan Journal of Science and Industrial Resources, 45: 82-85.

Laowansiri, T. (2008). Anaerobic degradation kinetic of reactive dyes with different carbon sources. J. Environ. Biolo, 29: 309-314.

Mishra. S., Prakash D. J. and Ramakrishma G. (2009). Characterization and Utilization of Malua oil Cake-A New adsorbent for removal of congo red dye from aqueous phase. Electronic Journal of Environment, Agricultural and Food Chemistry, 8(6): 425436. 